\title{
Effect of Different Pre-Cooling Methods on the Quality and Shelf Life of Broccoli
}

\author{
Vandana Kochhar* and Satish Kumar
}

Department of Processing and Food Engineering, Punjab Agricultural University, Ludhiana, Punjab, India

\begin{abstract}
This study aimed to evaluate the production of gas and volatile fatty acids when glycerin was used to replace four forage species through the use of a semi-automated technique in vitro. The experimental design included 4 treatments and 4 replications. The treatments consisted of increasing levels of glycerin $(0 \%, 30 \%, 50 \%$ and $70 \%)$, which was used to replace the forage plants elephant grass, sugar cane, corn silage and Brachiaria grass. Replacement of the Brachiaria and elephant grasses with glycerin affected the production of methane, carbon dioxide and ammonia nitrogen and had a positive effect on forage quality $(p<0.05)$. With the addition of glycerin, the values for acetate production decreased $(p<0.05)$; however, in elephant grass, when glycerin was increased to $50 \%$, the acetate production increased from 26.51 to 26.62 and $28.60(p<0.05)$. The inclusion of approximately $30 \%$ glycerin in the diet of ruminants is recommended because the inclusion of glycerin at this level had a qualitative effect on levels of methane, carbon dioxide, volatile fatty acids and ammonia nitrogen.
\end{abstract}

Keywords: Broccoli; Cold storage; Forced air cooling; Hydrocooling; Packaging; Pre-cooling; Room cooling

\section{Introduction}

Broccoli also known as Brassica oleracea L., Italica group, calabrese or sprouting broccoli, is a native of southern Europe. Morphologically, sprouting broccoli resembles cauliflower. The plant forms a kind of head, consisting of unopened green flower buds and thick fleshy flower stalks. The terminal head is rather loose, green in colour and the flower stalks are longer than the cauliflower. The head should be firm to hand pressure, compact, and the stalk cleanly cut to appropriate length for a particular grade standard or for crowns. The whole immature inflorescence (head) is the edible portion, with the floret tissue most often being consumed. The heads may be $15-25 \mathrm{~cm}$ in diameter and weighs $250-600 \mathrm{~g}$. Heads are cut off with about $15 \mathrm{~cm}$ of the stem attached. High quality broccoli has either a dark or bright green colour with closed flower buds. It is usually boiled or steamed. It can be consumed in the form of soup/salad or cooked vegetable. Temperature management is one of the most important factors affecting the post harvest life and quality maintenance in horticultural crops. Quality loss after harvest occurs as a result of physiological and biological processes, the rates of which are influenced primarily by the product temperature. The temperature at which you handle the product will directly affect the marketability of the produce. The shelf life of broccoli is usually terminated by yellowing of florets which detracts it from consumer acceptability. High temperature, low humidity and presence of ethylene gas accelerate yellowing. Maintaining high quality and extending shelf-life for long period requires broccoli to be kept at $0^{\circ} \mathrm{C}, 90-95 \% \mathrm{RH}$ immediately after harvesting and during subsequent post-harvest handling [1]. Broccoli is not sensitive to chilling temperature and should be stored as cold as possible without freezing at $0-2^{\circ} \mathrm{C}$. The colour is major quality attribute of vegetables considered to have the most impact on consumer selection of produce. Each vegetable respire differently (i.e. have different respiration rates) and continue respiration even after harvest. To maintain the quality (i.e. discoloration, flavor, aroma etc) the respiration rate should be reduced. The retention of green colour by vegetables after processing has been assessed as a measure of quality. Many factors affect the green colour and texture retention in vegetables such as temperature, relative humidity and atmospheric conditions. By controlling these conditions, the shelf life of produce can be enhanced. Studies were reported by many scientists [2-4] therefore there is a need to store broccoli under suitable conditions immediately after harvest so as to prolong its shelf life. The present study had been planned with the objective to study the effect of pre-cooling on the quality and shelf life of broccoli.

\section{Material and Methods}

\section{Procurement of broccoli}

Punjab Broccolil was sown in the farms of Department of Soil \&Water Engineering under the guidance of the expert from the Department of Vegetable, PAU Ludhiana. On maturity fresh broccoli florets were hand harvested early in the morning. Broccoli florets were kept in plastic crates to avoid any mechanical injury during transportation from the farm to the fruits and vegetables pilot plant. These heads were sorted out to remove any damaged or diseased crop and then manually graded for uniform size and colour of the experimental lot. The crop was then divided into two parts viz. broccoli with stalk and without stalk respectively.

\section{Pre-cooling of broccoli}

The crop was pre-cooled to $2^{\circ} \mathrm{C}$ using four methods viz. room cooling, forced air cooling, hydrocooling and package icing. The temperatures of all four cooling mediums were in the range of $0-1^{\circ} \mathrm{C}$. Thermocouple attached with digital meter was inserted into the broccoli to monitor the change in temperature of broccoli with time. Room cooling was done in the normal walk in cool rooms (Make: Motherson Zanotti) to cool the broccoli with cold air having wind speed of 0.5 $1 \mathrm{~m} / \mathrm{s}$. Plastic crates containing broccoli were well ventilated. Forced

*Corresonding author: Vandana Kochhar, Department of Processing and Food Engineering, Punjab Agricultural University, Ludhiana, Punjab, India, Tel: +918283824462; E-mail:vandana kochhar87@yahoo.com

Received December 17, 2014; Accepted February 16, 2015; Published February 23, 2015

Citation: Kochhar V, Kumar S (2015) Effect of Different Pre-Cooling Methods on the Quality and Shelf Life of Broccoli. J Food Process Technol 6: 424 doi:10.4172/2157-7110.1000424

Copyright: (c) 2015 Kochhar V, et al. This is an open-access article distributed under the terms of the Creative Commons Attribution License, which permits unrestricted use, distribution, and reproduction in any medium, provided the original author and source are credited. 
air cooling was similar to room cooling except that an additional fan was used to push the cool air at an air speed of $3-3.5 \mathrm{~m} / \mathrm{s}$ through the trays containing broccoli resulting in faster cooling than room cooling. The area of trays used was $66 \times 50 \mathrm{~cm}^{2}$. There was uniform cooling of broccoli kept in different trays. Hydro cooling was done using immersion hydro cooling method. A small tank with dimensions of $106 \times 46 \times 45 \mathrm{~cm}^{3}$ was filled with $160-165$ liters of chilled water having a temperature of $0-1^{\circ} \mathrm{C}$ in which broccoli was dipped to cool. The package icing was done using slurry method. A small tank with dimensions of $106 \times 46 \times 45 \mathrm{~cm}^{3}$ filled with slurry made by mixing $40 \%$ water and $60 \%$ finely crushed ice $(1: 1.5)$ was used in the study. The broccoli was completely dipped in it.

\section{Storage}

For storage purpose, pre-cooling of broccoli was done to $7 / 8^{\text {th }}$ cooling time. Pre-cooled broccoli with stalk and without stalk was cold stored in the Motherson Zanotti walk-in-cool chamber having dimension $174 \times 173 \times 216 \mathrm{~cm}^{3}$. Both temperature and relative humidity inside the chamber were adjusted with a differential of $1^{\circ} \mathrm{C}$ at desired levels. Broccoli was kept in the plastic crates having dimensions $50 \times 32 \times 28 \mathrm{~cm}^{3}$ placed inside the chamber.

\section{Physiological loss in weight (PLW)}

PLW was measured on initial weight basis. Initial weight of the sample was noted after pre-cooling and before keeping the sample for storage. The samples were weighed daily using citizen digital platform scale weighing balance. PLW was calculated by standard procedure as mentioned in AOAC [5] (Figure 1).

$$
\text { PLW }(\%)=\frac{\text { Initial weight }- \text { Final weight }}{\text { Initial weight }} \times 100
$$

\section{Color development}

Color is one of the most important parameter which describes the market quality of the product. Loss of green colour is a major limiting factor in shelf life reduction of stored broccoli. 'Yellowing' is the term used to describe the adverse condition of broccoli color quality degradation. Yellowing may be caused by over maturity at harvest, high storage temperatures and/or exposure to ethylene. Two types of

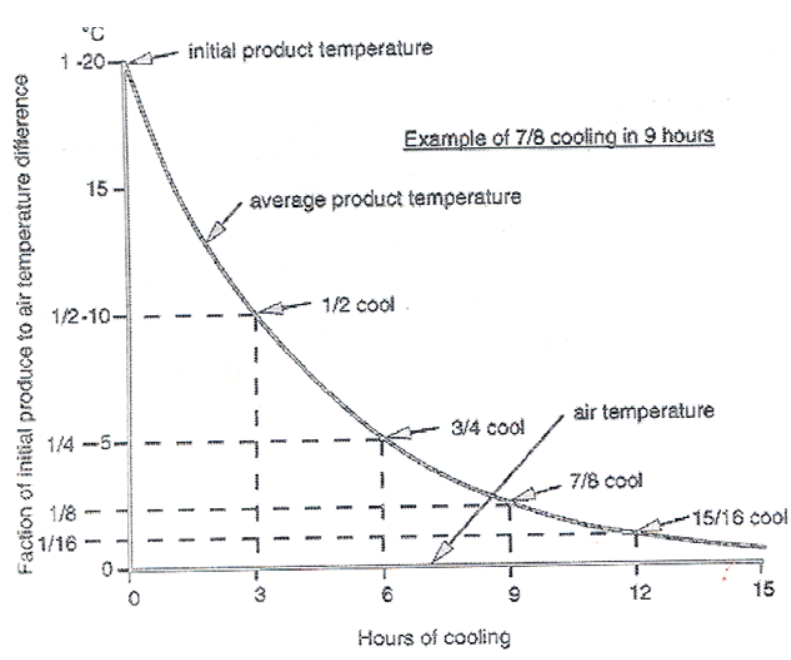

Figure 1: Typical time-temperature relationship for produce. yellowing occur in broccoli. Bead yellowing is due to senescence, while marginal yellowing develops during growth when florets are not exposed to light. Bead yellowing is a limiting factor in commercial marketability of broccoli. Color measurement gave an idea of comparative change in color in different treatments and with storage time. The color of pre-cooled stored sample was measured by using Miniscan XE plus Hunter Lab Colourimeter on daily basis. Broccoli color quality was assessed by the extent of yellowing of broccoli. The color of stored samples was recorded. The color of broccoli was measured with $\mathrm{L} a \mathrm{~b}$ scale. ' $L$ ' depicts lightness and its value varies from 0 to 100 ; ' $+a$ ' depicts redness and '-a' depicts greenness; ' $+b$ ' depicts yellowness and ' $-b$ ' depicts blueness. From these values of ' $L$ ', ' $a$ ' and ' $b$ ', the exact color of fruit was measured after comparing with the standard samples. Before measuring the color, the colorimeter was calibrated using white and black tiles provided along with equipment and standardized with white tile. The broccoli head was placed in close contact with the colourimeter lens so that the light which falls on the samples should reflect back and no light is transmitted to the surroundings [6]. Total colour difference was obtained using the relationship

$$
\Delta \mathrm{E}=\sqrt{\Delta \mathrm{L}^{2}+\Delta \mathrm{a}^{2}+\Delta \mathrm{b}^{2}}
$$

Where $\Delta \mathrm{L}, \Delta \mathrm{a}$ and $\Delta \mathrm{b}$ are deviations from $\mathrm{L}$, $\mathrm{a}$ and $\mathrm{b}$ values of fresh sample.

$$
\Delta \mathrm{L}=\mathrm{L}_{\text {sample }}-\mathrm{L}_{\text {standard }} ;
$$

$+\Delta \mathrm{L}$ means sample is lighter than standard, $-\Delta \mathrm{L}$ means sample is darker than standard.

$\Delta \mathrm{a}=\mathrm{a}_{\text {sample }}-\mathrm{a}_{\text {standard }}$;

$+\Delta$ a means sample is redder than standard, $-\Delta$ a means sample is greener than standard.

$$
\Delta \mathrm{b}=\mathrm{b}_{\text {sample }}-\mathrm{b}_{\text {standard }} \text {; }
$$

$+\Delta \mathrm{b}$ means sample is yellower than standard, $-\Delta \mathrm{b}$ means sample is bluer than standard.

The hue angle, chroma, and yellowing index (YI), which represents the purity of yellow colour were calculated according to the following equations:

$$
\begin{aligned}
& \text { Hue angle }=\tan ^{-1}(\mathrm{~b} / \mathrm{a}) \\
& \text { Chroma }=\left(\mathrm{a}^{2}+\mathrm{b}^{2}\right)^{1 / 2} \\
& \text { Yellowing Index }(\mathrm{YI})=142.86 \times(\mathrm{b} / \mathrm{L})
\end{aligned}
$$

\section{Texture analysis}

The hardness (firmness) of vegetable is another quality factor which decides its market quality. The textural properties of fresh and stored broccoli were measured with the help of texture analyser (TXXT2i) in the Post Harvest Engineering lab of the department. The texture analyser consisted of basic components namely hardware (load cell with platform to hold sample and moving head for holding probe and software (Texture Expert) for recording and calculating the results of the tests. The calibration of the texture analyser was done to check accurate sensing of load cell and probes. Texture (firmness) of broccoli was analysed in two ways viz compression test i.e force required to compress the broccoli head and cutting or shearing test i.e. force required to cut the floret finger [7] and user manual provided with the machine.

Force deformation ratio, a non-destructive test for whole fruit firmness was conducted using a cylindrical probe SMSP/75 mm 
in diameter coupled with load cell of $50 \mathrm{~kg}$ to a TX-XT2i Texture Analyzer. Each fruit was compressed vertically by $5 \mathrm{~mm}$. Force $(\mathrm{N})$, distance $(\mathrm{mm})$ and time $(\mathrm{sec})$ was recorded. From the force vs. time curves, firmness was defined as the maximum force. The following settings were selected.

Test Mode : Measure compression force,

Load cell : $50 \mathrm{~kg}$,

Test Speed : $2 \mathrm{~mm} \mathrm{~s}^{-1}$,

Test Distance : $5 \mathrm{~mm}$.

For measurement of hardness by cutting/ shear test, a sample of broccoli was placed on the platform and 'run a test' command was energized. The HDP/BS probe coupled with load cell of $50 \mathrm{~kg}$ cut the sample as per settings to generate the force time curve. The following settings were selected.

Test Mode : Measure cutting force,

Load cell : $50 \mathrm{~kg}$,

Test Speed : $2 \mathrm{~mm} \mathrm{~s}^{-1}$,

Test Distance : $5 \mathrm{~mm}$.

\section{Decay and shriveling}

Spoilage of broccoli was measured in terms of decay and shrivelling. Decay was measured in terms of freezing injuries which occur if broccoli is stored below $-1^{\circ} \mathrm{C}$ and florets appear dark and translucent, may turn brown after thawing and are very susceptible to bacterial decay. Bacterial decay is caused by soft rot causing organisms which affect broccoli heads and its shelf life. The weight of broccoli florets decayed at each interval was recorded and \% of decay with respect to initial weight was measured.

The term shrivelling suggests that the plant is dry and is an indirect loss. Weight loss results in shrivelling and is mainly associated with respiration and moisture evaporation through the skin. The shrivelling is usually found around the stem area, but in extreme cases the shrivelling may extend down the sides, especially along the suture. A few of the many terms used to describe shrivelling of fruits or vegetables are soft, limp, mealy, leathery, gritty, wooly, dullness, wrinkles and dry. There are no accepted instrumental methods for measuring each of these attributes. The weight of broccoli florets shrivelled at each interval was recorded and $\%$ of shrivelling with respect to initial weight was measured.

\section{Statistical analysis}

The observations taken from various experiments were analysed. The parameters studied were physiological loss in weight, colour, texture, decay and shrivelling. The data observed from various experiments were analyzed in terms of effect of pre-cooling treatments and storage period on the quality of cold stored broccoli. Pre-cooling treatments and storage period were selected as fixed factors. The quality parameters studied were physiological loss in weight, colour, shrivelling and textural properties and were chosen as dependent factors. The statistical analysis of the data was done by employing univariate analysis of variance (UNI-ANOVA) in general linear model using SPSS 11.5 (Statistical Package for Social Sciences). Analysis was done considering the main effects and two factor interactions. Means were computed and tested at 5 percent level of significance to arrive at the best results of the treatments.

\section{Results and Discussion}

\section{Physiological loss in weight (PLW)}

Effect of different pre-cooling methods on PLW (\%) of broccoli with stalk and without stalk under cold storage conditions are shown in Figure 2. A perusal of Figure 2 showed that PLW (\%) increased at a steady rate with the duration of storage. However the rate of loss in room cooled and forced air cooled samples were higher than hydrocooled and package iced samples. The PLW (\%) in cold stored broccoli with stalk after 21 days of storage were 8.1, 7.6, 7.0 and 6.6\% in room cooled, forced air cooled, hydrocooled and package iced samples respectively. The corresponding values of PLW (\%) in broccoli without stalk were 9.7, 8.8, 8.5 and $8.1 \%$ respectively. The results were corroborated by the Analysis of Variance (ANOVA) and showed significant effect of pre-cooling methods and storage duration on PLW values at 5\% level of significance. Thus PLW (\%) was highest for room cooled and least for package iced samples. It was further observed that broccoli without stalk showed higher PLW compared to broccoli with stalk (Figure 2). This may be due to more exposure to florets in broccoli without stalk. The results obtained are quite comparable with the previous studies. In forced air cooling method weight loss results from the vapor pressure difference between warm products and cold air [8]. Package icing is suitable for broccoli as it can tolerate the contact with ice and water $\left(0^{\circ} \mathrm{C}\right)[9]$. The ice takes out the heat from the commodity, causing it to melt while ensuring high relative humidity surrounding the produce [10]. Hydro-cooling in broccoli showed beneficial effects in terms of reduced weight loss and increased firmness. One great advantage of hydrocooling over air resides in the absence of crop mass loss during pre-cooling process and it may slightly rehydrate wilted product $[5,11-$ 13]. Thus from a consumer stand point, the quality of hydrocooled/ ice cooled commodities is high, while from the producer's stand point, the salable weight is high.
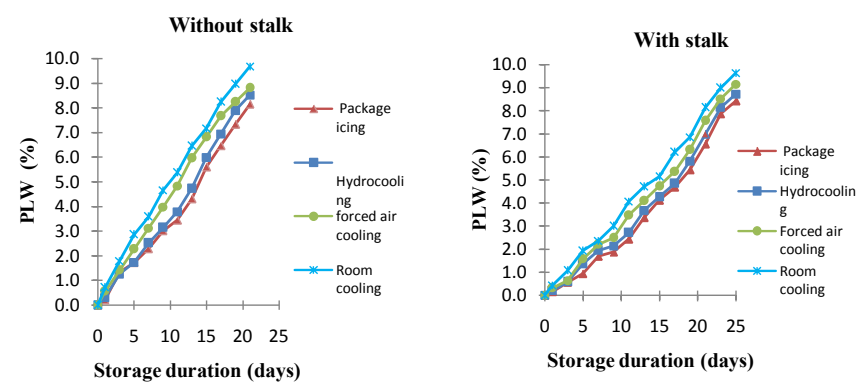

Figure 2: Effect of different pre-cooling methods on 'PLW' in cold stored broccoli.

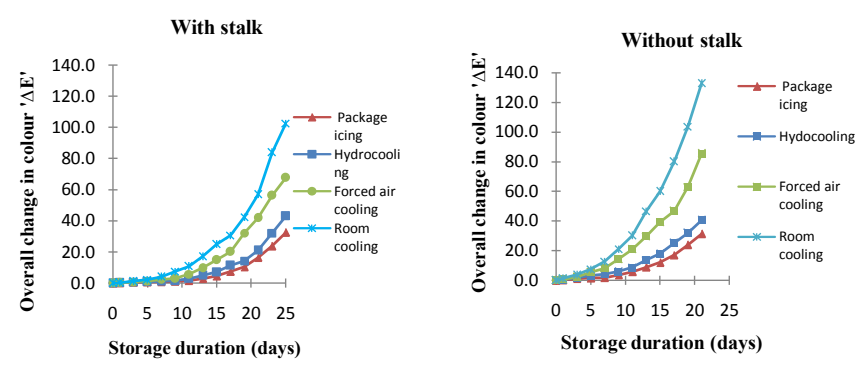

Figure 3: Effect of different pre-cooling methods on overall change in colour ' $\Delta \mathrm{E}$ ' in cold stored broccoli. 


\section{Colour changes}

The effect of colour changes in broccoli during storage pre-cooled with different methods were determined in terms of $\mathrm{L}$, a and $\mathrm{b}$. It was observed that among tristimulus values (L, a, b), "a" (green colour) was dominant parameter. The effect of different pre-cooling methods on ' $L$ ' value which means lightness in colour of broccoli with and without stalk under cold storage conditions is presented and trends are shown in Figure 3. A perusal of Figure 3 showed that L values increased at a steady rate with the duration of storage. However the increase in $\mathrm{L}$ values were more pronounced in room and forced air cooled samples than other two methods. The initial ' $L$ ' value was 23.53 . The $L$ value of broccoli with stalk after 21 days of storage were 31.31, 29.81, 26.84 and 25.78 in room cooled, forced air cooled, hydrocooled and package iced samples respectively. The corresponding peak $\mathrm{L}$ values of broccoli without stalk were $36.42,33.32,28.32$ and 27.52 respectively. Thus L value was highest for room cooled and least for package iced samples. It was further observed that broccoli without stalk showed higher L values as compared to broccoli with stalk (Figure 3). The results were corroborated by the Analysis of Variance (ANOVA) showing significant effect of pre-cooling time and storage duration on ' $\mathrm{L}$ ' values at $5 \%$ level of significance. The effect of different pre-cooling methods on 'a' values for broccoli with stalk and without stalk under cold storage conditions is presented and trends are shown in Figure 3. A perusal of Figure 3 showed that 'a' values increased at a steady rate with the duration of storage. Increase in 'a' value means loss of green colour which means loss in market quality of broccoli. The increase in 'a' value was sharper in room and forced air cooled samples than other two methods. The initial 'a' values was -3.30 . The 'a' value of broccoli with stalk after 21 days of storage were $-1.21,-1.39,-1.54$ and -1.63 in room cooled, forced air cooled, hydrocooled and package iced samples respectively. The corresponding 'a' values in broccoli without stalk were $-0.48,-1.43,-1.14$ and -1.51 respectively. Thus 'a' value was highest for room cooled and least for package iced samples. It was further observed that broccoli with stalk retained higher green colour as compared to broccoli without stalk as shown in Figure 3 The results were corroborated by the Analysis of Variance (ANOVA) and showed significant effect of pre-cooling time and storage duration on 'a' values at $5 \%$ level of significance.

The effect of different pre-cooling methods on ' $b$ ' values of broccoli with stalk and without stalk broccoli florets under cold storage duration condition are presented in and trends are shown in Figure 3. A perusal of Figure 3. showed that ' $b$ ' values which indicate yellowing of florets increased at a steady rate with the duration of storage. However the increase in ' $b$ ' values were more pronounced in room and forced air cooled samples than other two methods of pre-cooling. The initial ' $b$ ' value was 4.69. It was further observed that ' $b$ ' value of broccoli with stalk after 21 days of storage were $11.68,11.09,9.99$ and 9.68 in room cooled, forced air cooled, hydrocooled and package iced samples respectively. The corresponding ' $b$ ' values of broccoli without stalk after 21 days of storage were $14.26,13.16,12.02$ and 11.31 respectively. Thus ' $b$ ' value was highest for room cooled and least for package iced samples. It was further observed that broccoli without stalk showed higher ' $b$ ' values compared to broccoli with stalk as shown in Figure 3. The results were corroborated by the Analysis of Variance (ANOVA) and showed significant effect of pre-cooling time and storage duration on ' $b$ ' values at $5 \%$ level of significance.

The effect of different pre-cooling methods on ' $\Delta \mathrm{E}$ ' which showed overall change in colour of broccoli with stalk and without stalk under cold storage condition is presented in and trends are shown in Figure
3. A perusal of Figure 3. showed that ' $\Delta \mathrm{E}$ ' increased stalk after 21 days of storage were 56.87, 42.02, 21.07 and 16.37 in room cooled, forced air cooled, hydrocooled and package iced samples respectively. The corresponding colour change ' $\Delta E$ ' of broccoli without stalk after 21 days of storage was $132.84,85.54,40.69$ and 31.47 respectively. Thus ' $\Delta \mathrm{E}$ ' value was highest for room cooled and least for package iced samples. It was further observed that broccoli without stalk showed higher ' $\Delta \mathrm{E}$ ' values compared to broccoli with stalk especially in room and forced air cooled samples as shown in Figure 3. The results were corroborated by the Analysis of Variance (ANOVA) and showed significant effect of pre-cooling time and storage duration on overall change in colour ' $\Delta \mathrm{E}$ ' values at $5 \%$ level of significance.

The effect of different pre-cooling methods on chroma which indicates colour saturation or intensity of broccoli with and without stalk under cold storage conditions is presented and trends are shown in Figure 4. A perusal of Figure 4 showed that values of chroma increased at a steady rate with the duration of storage. However the increase in chroma value was more pronounced in room cooled and least in package iced samples. The initial chroma value was 5.73 . It was observed that the chroma value of broccoli with stalk after 21 days of storage were 11.74, 11.17, 10.10 and 9.81 in room cooled, forced air cooled, hydrocooled and package iced samples respectively. The corresponding chroma values of broccoli without stalk after 21 days of storage were $11.3,13.2,12.0$ and 11.4 respectively. Thus chroma value was highest for room cooled and least for package iced samples. It was further observed that broccoli without stalk showed higher chroma compared to broccoli with stalk as shown in Figure 4. The results were corroborated by the Analysis of Variance (ANOVA) and showed significant effect of pre-cooling time and storage duration on chroma values at $5 \%$ level of significance. The effect of different pre-cooling methods on hue angle which refers to a characteristic of colour and depends on the values of individual 'a' and 'b' of broccoli with stalk and without stalk under cold storage conditions are presented and trends are shown in Figure 5. A perusal of Figure 5 showed that hue angle value decreased at a steady rate with the duration of storage. However the decrease in hue angle was more pronounced in room cooled and least in package iced samples. The minimum hue angle was -54.86. It was observed that the hue angle of broccoli with stalk after 21 days of storage were $-84.0,-42.0,-81.2$ and -80.4 in room cooled, forced air cooled, hydrocooled and package iced samples respectively. The corresponding hue angle of broccoli without stalk was $-88.07,-83.79$, -84.58 and -82.39 respectively. Thus hue angle was highest for room cooled and least for package iced samples. It was further observed that broccoli without stalk showed high angle as compared to broccoli with stalk as shown in Figure 5. The results were corroborated by the Analysis of Variance (ANOVA) and showed significant effect of pre-cooling
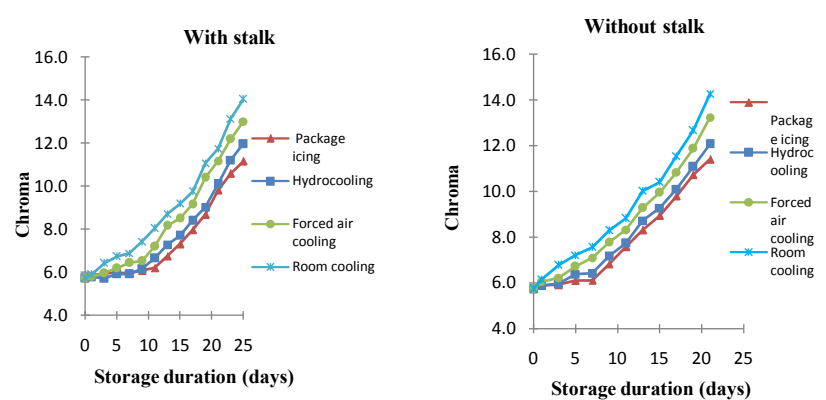

Figure 4: Effect of different pre-cooling methods on chroma in cold stored broccoli. 




Storage duration (days)

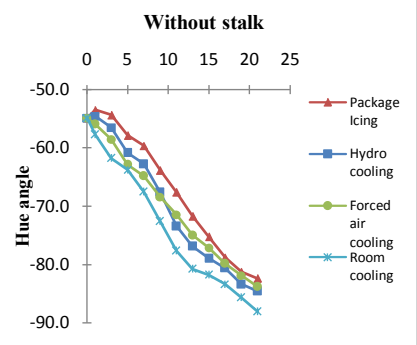

Storage duration (days)

Figure 5: Effect of different pre-cooling methods on hue angle in cold stored broccoli.
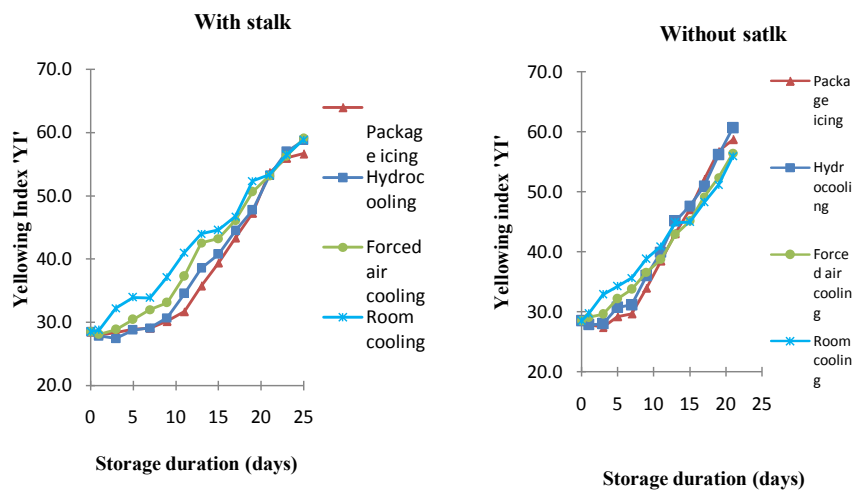

Figure 6: Effect of different pre-cooling methods on yellowing index in cold stored broccoli.

time and storage duration on hue angle at $5 \%$ level of significance.

The effect of different pre-cooling methods on Yellowing Index (YI) of broccoli with stalk and without stalk under cold storage conditions are presented in and trends are shown in Figure 6. A perusal of Figure 6 showed that values of 'YI' increased at a steady rate with the duration of storage but became almost same after about 18 days. Increase in 'YI' decreases the acceptability of broccoli florets for the consumer. This is well demonstrated by the fact that the maximum yellowing index (YI) value of broccoli with stalk after 21 days of storage were 53.23, 53.14, 53.17 and was 53.64 in room cooled, forced air cooled, hydrocooled and package iced respectively. The corresponding yellowing index (YI) values of broccoli without stalk after 21 days of storage was 55.93, $56.42,60.63$ and 58.71 respectively. Thus (YI) value was highest for room cooled and least for package iced samples. It was further observed that broccoli without stalk showed higher 'YI' values compared to broccoli with stalk (Figure 6) respectively especially in hydro/package iced broccoli while in other two methods there was no difference. The results were corroborated by the Analysis of Variance (ANOVA) and showed significant effect of yellowing index (YI) values on pre-cooling time and storage duration at $5 \%$ level of significance.

The colour depends upon various types of pigments in a crop. Yellowing in leafy and green vegetables has been attributed to peroxidase activity and lipoxygenase activity [14-16]. For these activities these two enzymes could be responsible for yellowing of broccoli. Low temperature are known to enhance phenolic content and metabolism in many plant tissues and organs and phenolic are known to affect the activity of lipoxygenase and peroxidase [17-19] Therefore, one possible affect of low temperature storage in broccoli

could be in enhancing phenolic levels of the tissue which could in turn inhibit oxidative injuries leading to chlorophyll loss when the broccoli is placed in elevated 'self' temperatures. It was concluded that package icing/ hydrocooling slowed down the colour change and the discoloration as compared to the room/ forced air cooling of broccoli.

\section{Texture}

The texture (firmness/hardness) was measured in terms of compression and cutting force. The effects of different pre-cooling methods on the hardness of broccoli with and without stalk are presented in and trends are shown in Figure 7. A perusal of Figure 7 showed that compression force decreased at a steady rate with the duration of storage. However the decrease in compression was slightly lower in room cooled and forced air cooled samples compared to hydrocooled and package iced samples. The fresh broccoli at the time of harvest had the compression force value of $1.54 \mathrm{~N}$ which reduced in all the pre-cooled broccoli samples during storage period. It was observed that the compression force of broccoli with stalk after 21 days of storage were $0.49,0.41,0.31$ and $0.26 \mathrm{~N}$ in room cooled, forced air cooled, hydrocooled and package iced samples respectively. The corresponding values of broccoli without stalk after 21 days of storage were $0.25,0.24,0.17$ and 0.13 respectively. Thus compression force (compactness of head) was higher in room/forced air cooled samples especially in broccoli with stalk compared to other two methods. Further broccoli with stalk had higher compression force compared to broccoli without stalk, while in other two methods the difference was less as shown in Figure 8. The results were corroborated by the Analysis of Variance (ANOVA) and showed significant effect of precooling time and storage duration on compression force values at $5 \%$ level of significance.

The effect of different pre-cooling methods on the cutting force of
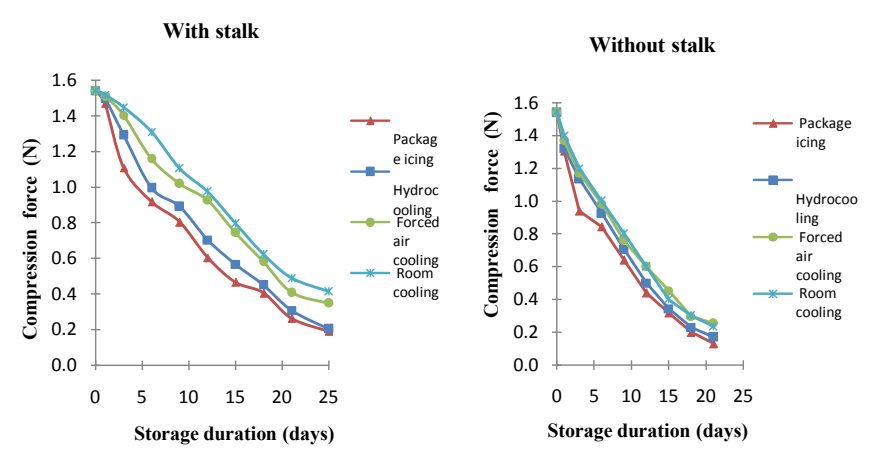

Figure 7: Effect of different pre-cooling methods on compression force in cold stored broccoli.


Figure 8: Effect of different pre-cooling methods on cutting force in cold stored broccoli. 

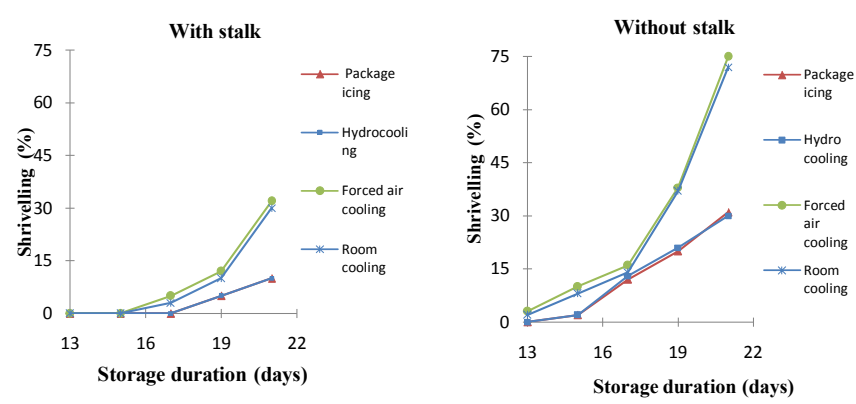

Figure 9: Effect of different pre-cooling methods on shrivelling in cold stored broccoli.

broccoli with stalk and without stalk is presented and trends are shown in Figure 8. A perusal of Figure 8 showed that cutting force decreased at a steady rate with the duration of storage in all pre-cooling method. However the decrease was slower in room cooled and forced air cooled than hydrocooled and package iced samples. The fresh broccoli at the time of harvest had the firmness value of $3 \mathrm{~N}$ which reduced in all the pre-cooling treatments during storage period. It was observed that the cutting force of broccoli with stalk after 21 days of storage were 1.37, $1.22,0.91$ and $0.80 \mathrm{~N}$ in room cooled, forced air cooled, hydrocooled and package iced samples respectively. The corresponding values of cutting force of broccoli without stalk after storage of 21 days were $1.36,1.11,0.90$ and 0.73 respectively. Thus cutting force required was higher in room/forced air cooled samples compared to hydro/package ice cooled samples. Moreover room/forced air cooled broccoli without stalk had higher cutting force compared to broccoli with stalk, while in other two methods there was no difference as shown in Figure 8. The results were corroborated by the Analysis of Variance (ANOVA) and showed significant effect of pre-cooling time and storage duration on cutting force values at $5 \%$ level of significance [3] observed differences in firmness in different pre-cooling treatments. Package iced and hydro cooled broccoli showed better results than forced air and room cooling treatments. This was due to an approximate $5 \%$ water uptake by broccoli during package icing and hydrocooling. However uptake was not reflected in this work since original weight was taken after the pre-cooling treatments. A $5 \%$ water uptake (by weight) gives package iced and hydro cooled broccoli a specific advantage over forced air cooled and room cooled broccoli in terms of maintaining firmness. [8] Observed that the use of hydro-cooling broccoli had beneficial effects in terms of reduced weight loss and increased firmness.

\section{Decay and shriveling}

Incidence of decay was observed in terms of diseases like freezing injury in which florets appear dark and translucent, may turn brown after thawing, fungal growth as gray mold rot and black mold rot. No decay was found in broccoli with and without stalk. Shriveling loss was difficult to determine but was determined on the basis of loss of shine or dullness, fingers falling, firmness loss and wrinkles. The effect of different pre-cooling methods on the shrivelling of broccoli with stalk and without stalk is presented in Figure 9. It was observed that shriveling values of broccoli with stalk after 21 days of storage were $30,32,10$ and $10 \%$ in room cooled, forced air cooled, hydrocooled and package iced samples respectively. The corresponding shriveling value of broccoli without stalk was $72,75,30$ and $31 \%$ respectively. Thus shriveling values was higher in room/forced air cooled samples compared to other two methods both in broccoli with and without stalk. Moreover broccoli without stalk had higher values than broccoli with stalk as shown in Figure 9. The results were corroborated by the Analysis of Variance (ANOVA) and showed significant effect of pre-cooling method and storage duration on shrivelling at $5 \%$ level of significance. This was due to an approximate $5 \%$ water uptake by broccoli during package icing and hydrocooling. Cells can suck water from outside through the cell wall which gives the desirable crispness, firmness and turgidity for the crop tissue $[8,20]$. Thus high water content keeps its juiciness and nutritive value high. A 5\% water uptake (by weight) gave package iced and hydrocooled broccoli a specific advantage over forced air cooled and room cooled broccoli in terms of maintaining firmness at least for 18 and 15 days of storage in broccoli with and without stalk at $0 \pm 1{ }^{\circ} \mathrm{C}$ storage and $99 \%$ relative humidity without adversely affecting the quality.

\section{Conclusion}

Based on these observations, it was concluded that package icing and hydrocooling were better methods of cooling compared to forced air cooling and hydrocooling. The shelf-life and quality of broccoli could be maintained up to 18 days in broccoli with stalk and 15 days in broccoli without stalk respectively under cold storage conditions.

\section{References}

1. Tan SC, Berston J, Haynes $Y$ (1992) Packaging systems for sea freight of broccoli. Journal of Crops and Horticultural Science 20: 167-172.

2. King GM, Morris SC (1994) Physiological changes in broccoli during early postharvest senescence and postharvest continuum. J AM Soc Horticultural Science 119: 270-275.

3. Gillis SL, Tiovonen PMA (1995) Cooling method influences the postharvest quality of broccoli. Horticulture Science $30: 313-315$.

4. Finger FL, Endre L, Mosquim PR, Puiatti M (1999) Physiological changes during postharvest senescence of broccoli. Pesq Agropec Bras 34: 37-39.

5. AOAC (1994) Official Methods of Analysis. Association of Official Analytical Chemists. Virginia, USA.

6. Gormley R (1974) Chill storage of mushrooms. J of the Science of Food and Agriculture 26: 401-411.

7. Breene WM, Thomas GB (1975) Development and application of a texture measurement procedure for textured vegetable protein. Journal of Texture Studies 6: 459-472.

8. Lisa Kitinoja and James Gorny (1998) Postharvest technology of fruits and vegetable Produce Marketers. Division of Agriculture and Natural Resources, University of California.

9. Kays JS (1997) Postharvest physiology of perishable plant products. Exon Press, Athens, Georgia.

10. Sargent SA, Talbot MT, Brecht JK (1988) Evaluating Precooling Methods for Vegetable Packinghouse Operations. Proc Fla. State Hort Soc 101: 175-182.

11. Klieber A, Jewell L, Simbeya N (1993) Ice or an ice replacement agent does not improve refrigerated broccoli storage at $1^{\circ} \mathrm{C}$. Hort Technology 3: 317-18.

12. Thompson KA (2003) Fruits and vegetables: harvesting, handling and storage (2nd edition), Oxford Blackwell Science, UK

13. USDA (2004) The Commercial Storage of Fruits, Vegetables and Florits and Nursery Stocks. USDA Agriculture Handbook Number 66.

14. Baardesth, P, Elbe JHV (1989) Effect of ethylene, free fatty acid, and some enzyme systems on chlorophyll degradation. Journal of Food Science 54: 1361-1364.

15. Yamauchi N, Wtada AE (1991) Regulated chlorophyll degradation in spinach leaves during storage. Journal of Americal Society for Horticultural Science 116: 58-62.

16. Zhuang H, Hildebrand DF, Barth MM (1995) Senescence of broccoli buds is related to changes in lipid peroxidation. Journal of Agricultural and Food Chemistry 43: 2585-2591. 
Citation: Kochhar V, Kumar S (2015) Effect of Different Pre-Cooling Methods on the Quality and Shelf Life of Broccoli. J Food Process Technol 6: 424. doi:10.4172/2157-7110.1000424

Page 7 of 7

17. Jeffrey B. Harborne, Van Sumere GF (1975) The Chemistry and Biochemistry of Plant Protiens. Academic Press, London.

18. Friend J, Rhodes MJC (1981) Recent advances in the Biochemistry of Fruits and Vegetables, Academic Press, London.
19. Oszmianski J, Lee CY (1990) Inhibitory effect of phenolics on carotene bleaching in vegetables. Journal of Agricultural and Food Chemistry 38: 688 - 690

20. Martens M, Baordseth P (1987) Sensory quality. In: Weichmann Journal of Postharvest Physiology of Vegetables. Pp 597 Marcel Dekker, Inc. New York, USA 